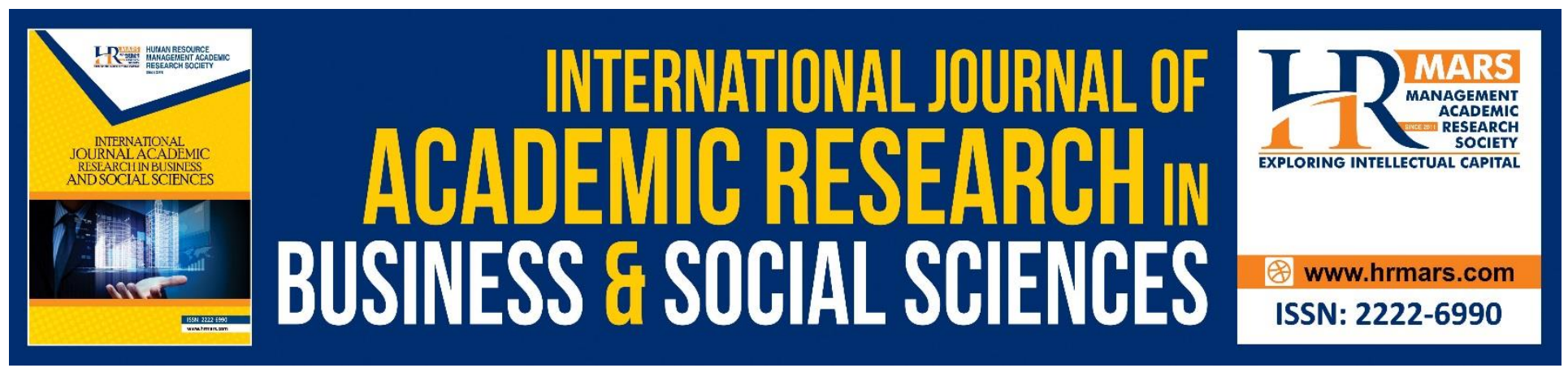

\title{
The Role of Discipline Learning as a Mediator in Relationship between Learning Styles with Academic Achievement
}

\author{
Zamri Chik, Abdul Hakim Abdullah
}

To Link this Article: http://dx.doi.org/10.6007/IJARBSS/v8-i11/4960

DOI: 10.6007/IJARBSS/v8-i11/4960

Received: 29 Sept 2018, Revised: 21 Oct 2018, Accepted: 16 Nov 2018

Published Online: 26 Nov 2018

In-Text Citation: (Chik \& Abdullah, 2018)

To Cite this Article: Chik, Z., \& Abdullah, A. H. (2018). The Role of Discipline Learning as a Mediator in Relationship between Learning Styles with Academic Achievement. International Journal of Academic Research in Business and Social Sciences, 8(11), 836-845.

Copyright: (C) 2018 The Author(s)

Published by Human Resource Management Academic Research Society (www.hrmars.com)

This article is published under the Creative Commons Attribution (CC BY 4.0) license. Anyone may reproduce, distribute, translate and create derivative works of this article (for both commercial and non-commercial purposes), subject to full attribution to the original publication and authors. The full terms of this license may be seen

at: http://creativecommons.org/licences/by/4.0/legalcode

Vol. 8, No. 11, 2018, Pg. 836 - 845

http://hrmars.com/index.php/pages/detail/IJARBSS

JOURNAL HOMEPAGE

Full Terms \& Conditions of access and use can be found at http://hrmars.com/index.php/pages/detail/publication-ethics 


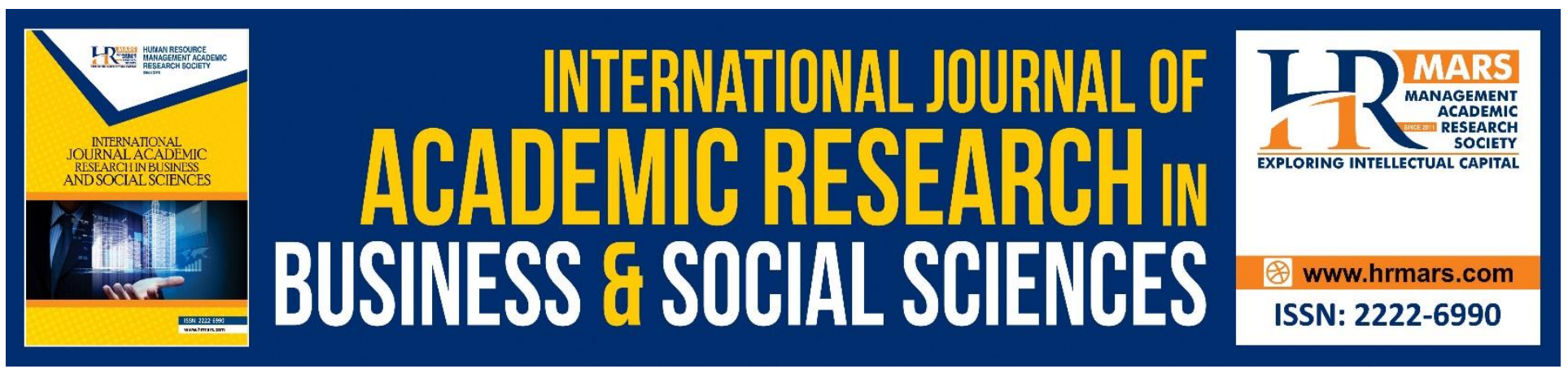

\title{
The Role of Discipline Learning as a Mediator in Relationship between Learning Styles with Academic Achievement
}

\author{
Zamri Chik, Abdul Hakim Abdullah \\ Faculty of Islamic Contemporary Studies, Universiti Sultan Zainal Abidin, Gong Badak Campus, \\ 21300 Kuala Terengganu, Terengganu, Malaysia
}

\begin{abstract}
This mediator is a mechanism that describes how one variable can affect other variables. Thus, this study was conducted to explain the role played by mediators to build discipline learning as a link between learning styles and student achievement. A total of 260 forms of four students, taking an additional Mathematics course at a secondary school in Kuala Terengganu District. Data were analyzed using version 21.0 from IBM-SPSS-AMOS (Package Statistics for Social Sciences - Moments Structure Analysis). The findings indicate that the mediator-linked test is supported and the type of mediator relation is partial mediation relationship because both indirect effects for learning style constructions on the construction of learning discipline and the construction of disciplined learning against the construction of academic achievement are significant, and the direct impact of learning styles built on the construction of academic achievement is also significant. Bootstrapping findings in this study are partial mediation effects because their direct effects are also significant and consistent with the findings of mediator linking tests in the testing procedure.
\end{abstract}

Keywords: Learning Styles, Mediator, Structural Equation Modeling (SEM), Additional Mathematics, Bootstrapping.

\section{INTRODUCTION}

The purpose of this article is to explain the role played by mediators to build disciplinary learning as the relationship between learning styles and the form of four students at academic level, who take extra mathematics courses in secondary schools in Kuala Terengganu district. The basic concept of this mediator model is a mechanism that describes how one variable affects other variables (Baron \& Kenny, 1986; James \& Brett, 1984). According to MacKinnon (2007), complex relationships can be demonstrated by the existence of a third variable that lies between the relationship between independent variables (IV) and the dependent variable (DV). This type of relationship is known as a mediator, and the third variable is known as the mediator variable (M). The concept of mediators as 
an indirect effect, intervention variables or intermediate effects (Robins, Kraley \& Krueger, 2007). To illustrate this more comprehensive model of mediator can be seen in Figure 1 below.

Based on Figure 1 below, the translation can be obtained simultaneously with the conceptual concept of the mediator model. The first model shows a simple relationship between IV and DV. To prove the existence of a mediator model, the relationship between IV and DV can not be zero. This is because, if there is no correlation between IV and DV, then it can not measure the mediator effect. The second model illustrates the existence of a mediator model based on the direct impact model between IV and DV through mediator (M) using paths $b$ and c. If IV and DV are correlated via $M$, path a' becomes zero, and the correlation between IV and DV can be said that variable M plays a full role as a mediator. If a' strip is not zero, but smaller than a strip, then it can be argued that the function of the variable mediator $\mathrm{M}$ is partial.

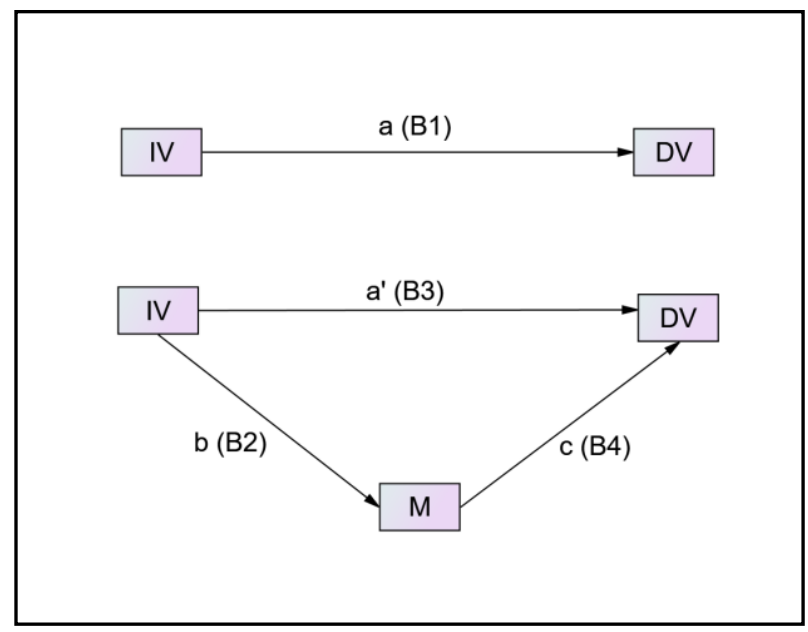

Figure 1: Mediator Path

Note: $B_{1}, B_{2}, B_{3}$ and $B_{4}$ are regression coefficients of regression equations 1,2 , and 3 that are used to predict paths.

(Source: Baron \& Kenny, 1986).

James \& Brett (1984) states that full mediators are linear causal correlations. This principle is described in the form $\mathrm{x} \rightarrow \mathrm{m} \rightarrow \mathrm{y}$, where $\mathrm{x}$ antiseden, $\mathrm{m}$ is the mediator and $\mathrm{y}$ is the result (consequence). Antisen $\mathrm{x}$ is expected to indirectly affect $\mathrm{y}$, because it must go through the mediator $\mathrm{m}$. If there is a complete mediator process, it is assumed that the model is linear causality. Therefore, it is estimated that $x$ has a direct effect on $m$, where $m$ has a direct impact on $y$, and $x$ does not affect $y$ at $m$ if constant or constant. Baron \& Kenny (1986) states that there are four conditions that must be met in order to describe the mediator model. Three statistical models are as follows:

1) $D V=B_{0}+B_{1}$ (IV)

2) $M=B_{0}+B_{2}$ (IV)

3) $D V=B_{0}+B_{3}(I V)+B_{4}(M)$

Of the three statistical models can be understood as follows: 
1) Equation 1 illustrates the basic relationship between IV and DV and estimates the magnitude of $B_{1}$, which means the first model path coefficient in Fig. 1.

2) Equation 2 gives an approximation of $B_{2}$ (the relationship between IV and $M$ ) intending to explain the path coefficient $b$, which is seen in model 2 in Figure 1.

3) Equation 3 illustrates the path $c\left(B_{4}\right)$ (the relationship between $M$ and DV) in the second model and $B_{3}$ which illustrates a' path in Fig. 1.

After estimating the parameters, then to say whether the variable acts as a mediator, it is necessary to consider the following 4 conditions:

1) Relationship IV and DV are significant (equation 1).

2) Relationship IV and $M$ are significant (equation 2).

3) The relationship between $M$ and DV is also significant after control IV.

4) The role of IV for DV decreases after $M$ is controlled.

By fulfilling these four conditions, the role of IV in DV is less than that of the IV and M versus DV, it is said that $\mathrm{M}$ is the mediator variable, and the proposed model proves to be a mediator model. Therefore, the role of the mediator variable describes the effect of several variables on a variable. That's not all variables are located as variables that cause changes to other variables.

\section{SEM Approach to Testing Mediator Models}

The SEM approach is selected if the researcher wants to know more than one variable measured from the latent variable. Suppose there are latent predictive variables $(A)$, centralized centralized mediator variables $(B)$ and hypothetical variables $(C)$. The first to be measured is the direct effect of $A \rightarrow C$. If the fit results match the direct impact model, proceed with testing the overall compatibility of the model ie $A \rightarrow B \rightarrow C$. If for the whole model is appropriate, then continue by testing the matching model $A \rightarrow B$ and $B \rightarrow C$, to determine the coefficient of route analysis. In this case, all routes $(A \rightarrow$ $C, A \rightarrow B$ and $B \rightarrow C$ ) on model $A \rightarrow B \rightarrow C$ must be significant (analogy of previous regression model).

The final step to using SEM in testing the mediator model is to test the model $A \rightarrow B \rightarrow C$ under two conditions: (1) if path $A \rightarrow C$ is directed to 0 and (2) if path $A \rightarrow C$ is not directed. An appropriate test is performed by looking at the differences between the two chi-square models. The mediator effect occurs if the addition of $A \rightarrow C$ to the fixed model does not improve the matching of the model. In other words, the importance of route $A \rightarrow C$ is reduced to unimportant when the mediator is involved in the analysis (analogy of the regression approach) (Hersen \& Gross, 2008).

Figure 2 shows the conceptual model of research, where IV is a learning style built, the mediator is the shaper of the discipline of learning, while DV is a constructive achievement of student academic achievement. 


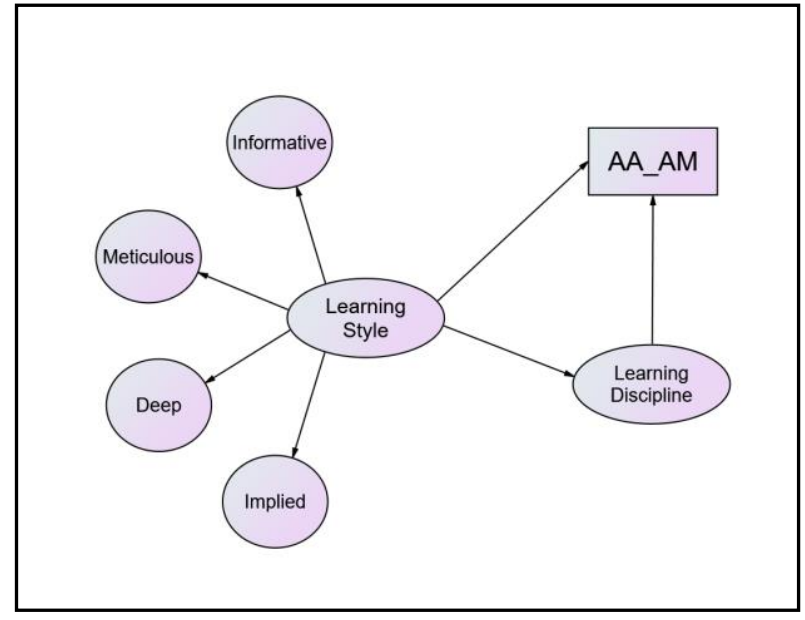

Figure 2: Conceptual Model

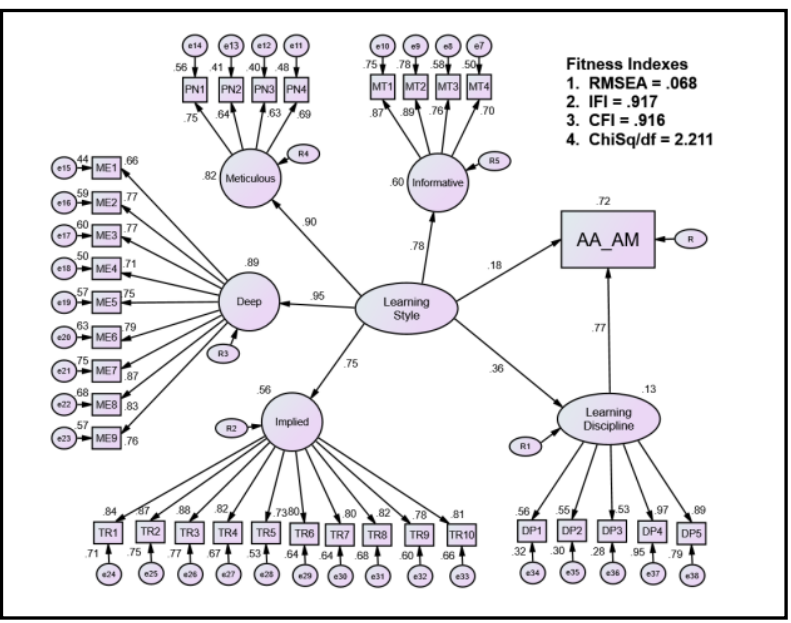

Figure 3: SEM Findings Indicates Standard Regression Value Between Construction (Standarddized Estimates)

a) An important summary of the SEM findings in Figure 3 (standard regression):

1) The value of $R^{2}$ for the construct "Learning Discipline" (LD) is 0.13 . This shows the predecessor construction in the model (see arrow) of "Learning Style" (LS) accounted for $13 \%$ of the "Learning Discipline" (LD) among the populations in the study.

2) The value of $R^{2}$ to construct "AA_AM" is 0.72 . This shows two predictor constructions in the model (see arrow) ie "Learning Style" (LS) and "Learning Discipline" (LD) accounted for 72\% for "AA_AM" among the populations in the study.

Figure 4 shows the findings of the regression values between the constructs in the model, to build the required regression equations and make the hypothesis testing later. 


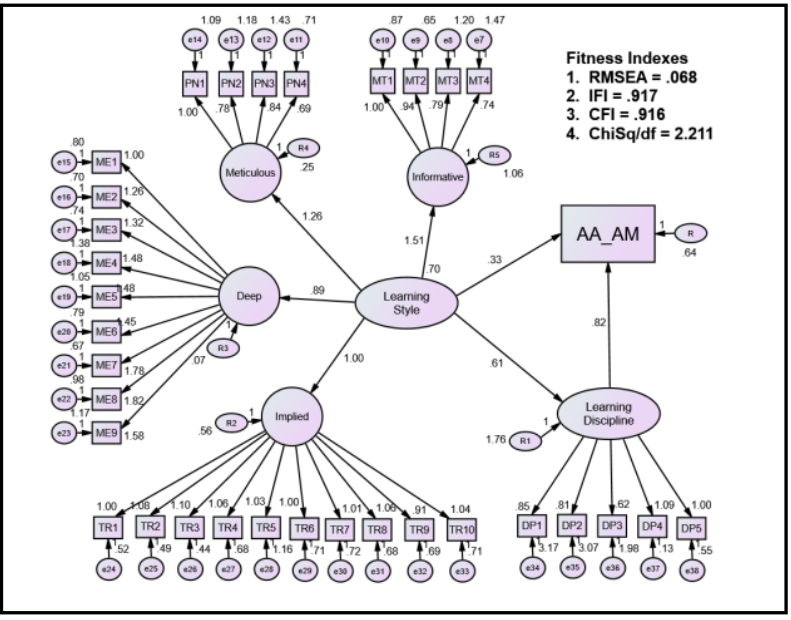

Figure 4: SEM Findings Indicate the Regression Value Between Construction (Unstandarddized Estimates)

\section{b) An important summary of the SEM findings in Figure 4 (regression value):}

The regression equations for the Learning Discipline (LD) and AA_AM are as follows:

1) $L D=0.61 \mathrm{LS}\left(R^{2}=0.13\right.$ or $\left.13 \%\right)$

2) AA_AM $=0.33 L S+0.82 L D\left(R^{2}=0.72\right.$ or $\left.72 \%\right)$

Furthermore, the researcher will test every hypothesis proposed in this research. Table 1 shows estimates of the direct effects of the effects of each independent construction on the constructs in the model as shown in Figure 4 above.

Table 1: Regression Coefficients Between Construct Value and Probability ( $\mathrm{p}$ )

\begin{tabular}{|r|c|l|c|c|c|c|c|}
\hline Constructs & & \multicolumn{1}{|c|}{ Constructs } & Estimate & S.E. & C.R. & P & Label \\
\hline Learning_Discipline & $\begin{array}{c}<- \\
--\end{array}$ & Learning_Style & 0.612 & 0.117 & 5.235 & 0.001 & Significant \\
\hline AA_AM & $\begin{array}{c}<- \\
--\end{array}$ & Learning_Discipline & 0.819 & 0.048 & 17.056 & 0.001 & Significant \\
\hline AA_AM & $\begin{array}{c}<- \\
--\end{array}$ & Learning_Style & 0.332 & 0.075 & 4.406 & 0.001 & Significant \\
\hline
\end{tabular}

\section{Mediator Analysis for Learning Discipline}

Table 2 shows the hypothesis testing of the mediator effect of the "Learning Discipline" (LD) built into the relationship between independent constructions (Learning Styles - LS) and dependent construction (AA_AM).

Table 2: Hypothesis Test of Mediator Effect Learning Discipline to Build 
INTERNATIONAL JOURNAL OF ACADEMIC RESEARCH IN BUSINESS AND SOCIAL SCIENCES Vol. 8, No. 11, Nov, 2018, E-ISSN: 2222-6990 @ 2018 HRMARS

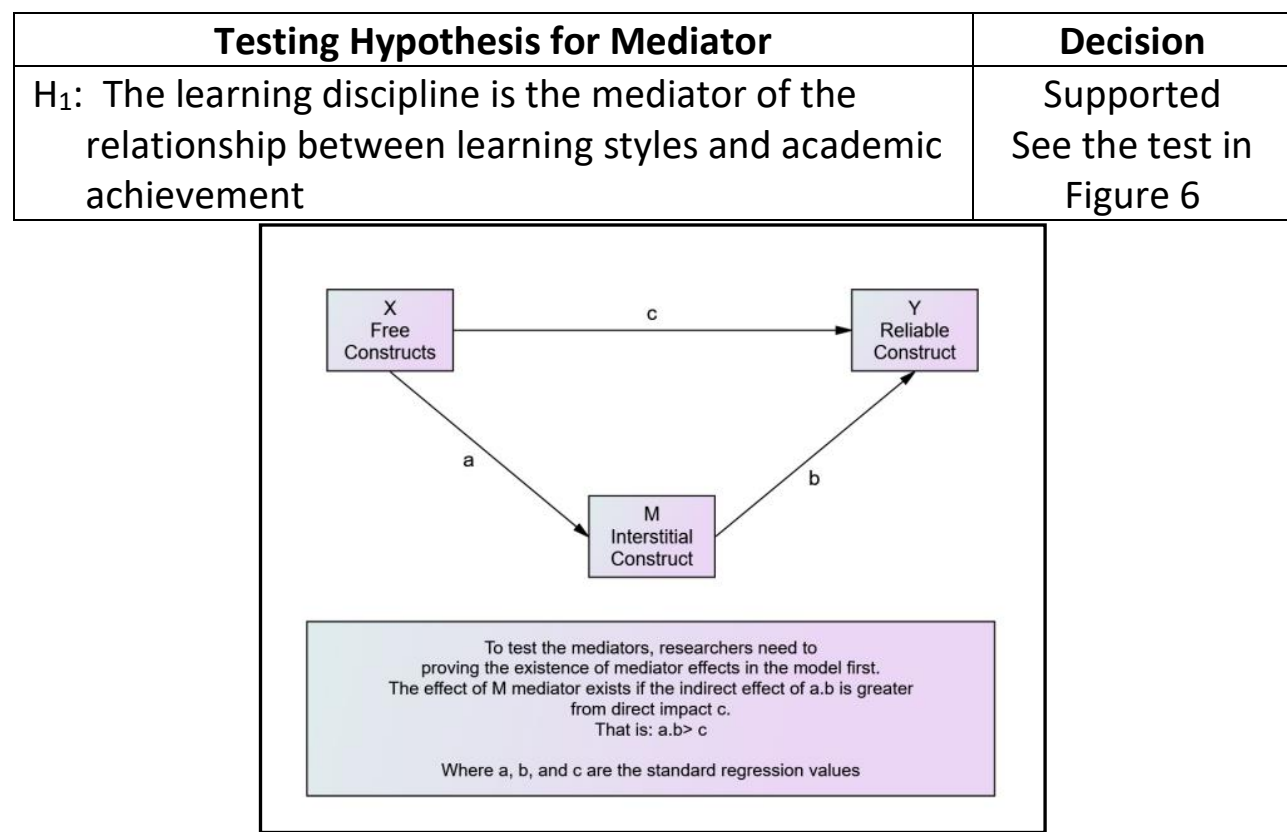

Figure 5: Testing the Mediator Effect Hypothesis M in Model A

The hypothesis test of the constructive mediator effect of the "Learning Discipline" in Table 1 is shown in Figure 6. This study uses a mediator effect testing process as suggested by Awang (2014; 2015; Awang et al., 2015a; Kashif et al., 2016). This method requires a triangular diagram as shown in Figure 5. The values of $a, b$ and $c$ need to be extracted from the graphical output regression weight graph as shown in Figure 5.

\section{Learning Discipline Is a Mediator Relationship between Learning Styles and Academic Achievement}

Figure 6 shows all the standard regression values that connect the three routes to test the mediator hypothesis. Figures 6 and Table 2 illustrate the mediator correlation test procedure in the model according to Awang $(2012 ; 2014 ; 2015)$. In this model "Learning Discipline" (LD) is an intermediate variable, "Learning Style" (LS) is an independent variable and "Academic Achievement" (AA_AM) is a dependent variable. The test procedure is as follows:

1) Direct effect $=0.18$

2) Indirect effect $=0.36 \times 0.77=0.277$

3) Indirect effect > direct effect, then the mediator applies between LS and AA_AM.

4) Both indirect effect paths between LS and LD and LD with AA_AM are significant.

5) The type of mediator effect in this study was a partial mediator because the direct effects between LS and AA_AM were significant (see Table 1). 
INTERNATIONAL JOURNAL OF ACADEMIC RESEARCH IN BUSINESS AND SOCIAL SCIENCES Vol. 8, No. 11, Nov, 2018, E-ISSN: 2222-6990 @ 2018 HRMARS

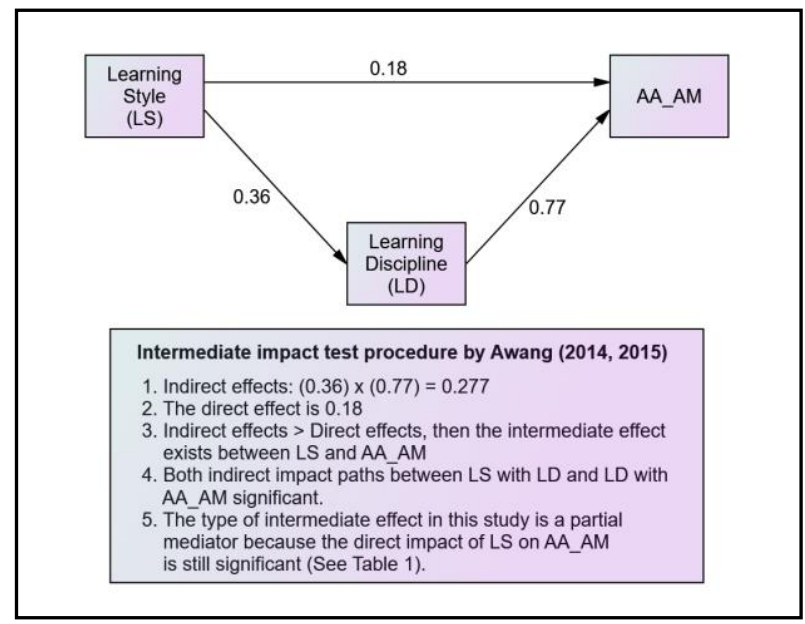

Figure 6: Impact Test of LS-LD-AA_AM Testing Mediator

Based on the above test, the results show that the mediator link test is supported and the type of mediator relationship is Partial Mediation because both are indirect effects of "Learning Style" (LS) on "Learning Discipline" (LD) and "Learning Discipline" (LD) to "Academic Achievement" (AA_AM) is significant, and the direct effect of "Learning Style" (LS) on "Academic Achievement" (AA_AM).

To verify the mediator test, the researcher should perform a bootstrap test using the re-sampling size ( $n=1000$ ) (Awang, 2012; 2015; 2015). In this study, researchers selected the re-sampling size proposed by Awang $(2012 ; 2014 ; 2015)$ by correcting the corrected $95 \%$ bias. It aims to derive direct and indirect effects along with their respective probability $(p)$ values. The investigators then compared the findings of bootstrap findings from mediatorial relationships with findings tested by conventional procedures. The importance of direct effects is to know the type of mediator effect that exists, whereas for indirect effect is to know the existence of mediator effect (Awang, 2015; 2015). Table 3 below shows the findings of bootstrapping for the Learning Style (LS) constructs on the constructs of Academic Achievement (AA_AM).

The results of bootstapping in Table 3 show the direct effect of the same path of 0.108 , whereas the indirect effect of Learning Styles (LS) on Academic Achievement (AA_AM) is 0.276. This indicates that there is influence of Mediator Learning Discipline (LD) because the indirect effect (ie through LD) is greater than the direct impact (ie without via LD) between the relationship between LS and AA_AM. The findings also suggest a direct impression and a significant indirect effect. The significance of the indirect effect indicates the role of the mediator, instead it can be formulated that the bootstrapping findings in Table 3 are partial mediation effects because both direct and indirect impacts are significant and consistent with the findings of the mediator link test in the test procedure. This means the hypothesis $\mathrm{H}_{1}$ is supported. 
INTERNATIONAL JOURNAL OF ACADEMIC RESEARCH IN BUSINESS AND SOCIAL SCIENCES Vol. 8, No. 11, Nov, 2018, E-ISSN: 2222-6990 (C) 2018 HRMARS

Table 3: Bootstapping Findings Between Construct Studies

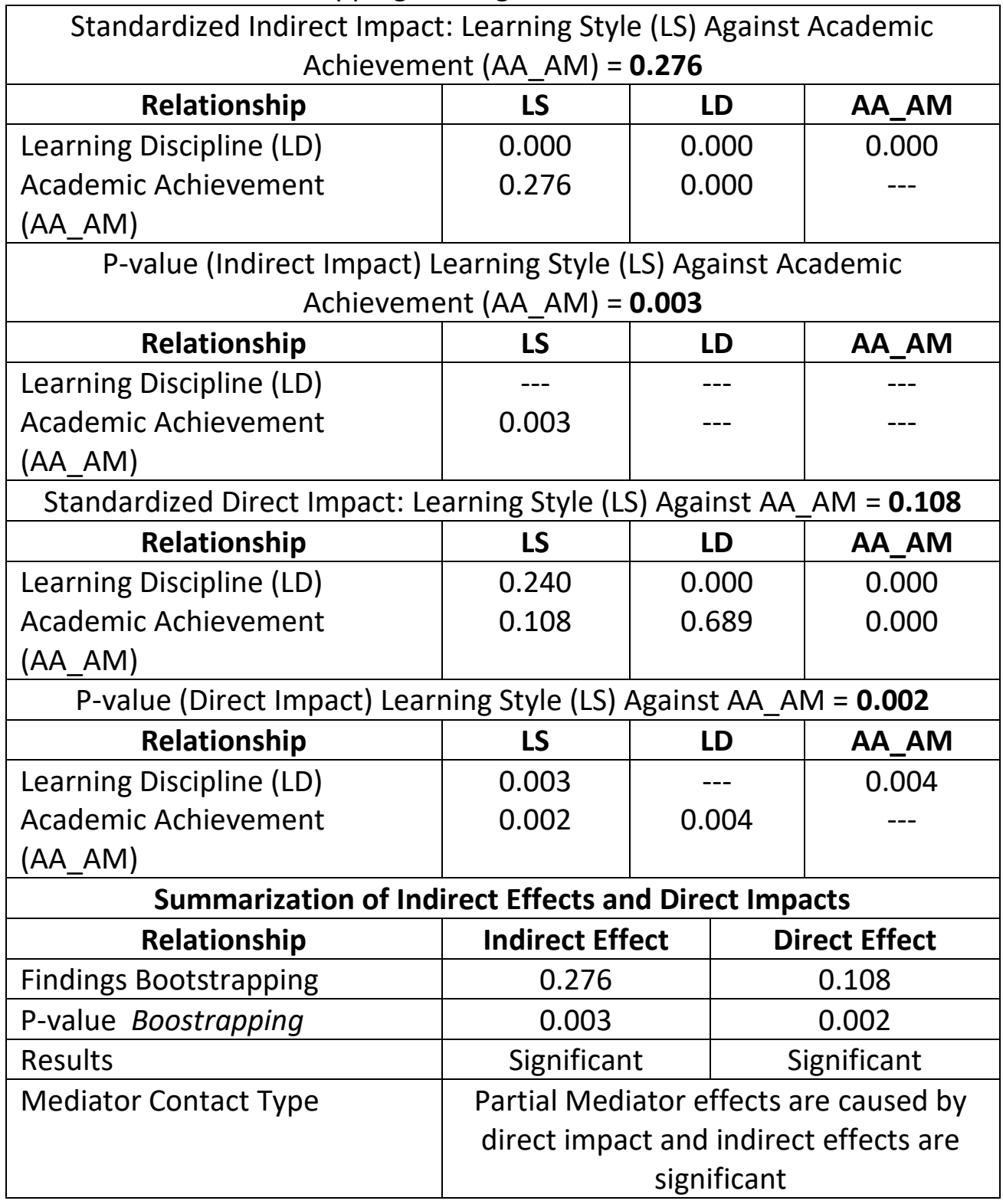

\section{Conclusion}

Overall, the findings indicate that the learning discipline is a mediator in the relationship between learning styles and academic achievement student.

\section{References}

Awang, Z. (2012). Research methodology and data analysis. Penerbit Universiti Teknologi MARA Press (UiTM Press).

Awang, Z. (2014). A handbook on SEM for academicians and practitioners: the step by step practical guides for the beginners. Bandar Baru Bangi, MPWS Rich Resources 
INTERNATIONAL JOURNAL OF ACADEMIC RESEARCH IN BUSINESS AND SOCIAL SCIENCES

Vol. 8, No. 11, Nov, 2018, E-ISSN: 2222-6990 @ 2018 HRMARS

Awang, Z. (2015). SEM Made Simple: A Gentle Approach to Learning Structural Equation Modeling. Bandar Baru Bangi, MPWS Rich Resources.

Awang, Z., Afthanorhan, A., Mohamad, M., \& Asri, M. A. M. (2015a). An evaluation of measurement model for medical tourism research: the confirmatory factor analysis approach. International Journal of Tourism Policy, 6(1), 29-45.

Baron, R. M., \& Kenny, D. A. (1986). The moderator mediator variable distinction in social psychological research: Conceptual, strategic, and statistical considerations. Journal of Personality and Social Psychology, 51, $1173-1182$.

Byrne, B. M. (2013). Structural equation modeling with AMOS: Basic concepts, applications, and programming (2nd ed.). New York: Routledge.

Chua, Y. P. (2014d). Kaedah dan statistik penyelidikan: Ujian regresi, analisis faktor, dan analisis SEM, Buku 5 (edisi 2). Selangor: McGraw-Hill Education (Malaysia) Sdn. Bhd.

Hoque, A.S.M.M, Awang, Z., Jusoff, K., Salleh, F., and Muda, H (2017). Social Business Efficiency: Instrument Development and Validation Procedure using Structural Equation Modelling. International Business Management, 11(1), 222-231.

Hersen, M. \& Gross, A.M. (2008). Handbook of clinical psychology, volume 2: children and adolescents, New Jersey: JohnWiley \& Sons, Inc.

James, L. R., \& Brett, J. M. (1984). Mediators, moderators, and tests for mediation. Journal of Applied Psychology, 69, $307-321$.

Kashif, M., Samsi, S. Z. M., Awang, Z., \& Mohamad, M. (2016). EXQ: measurement of healthcare experience quality in Malaysian settings: A contextualist perspective. International Journal of Pharmaceutical and Healthcare Marketing, 10(1), 27-47.

Kline, R. B. (2016). Principles and practice of structural equation modeling (4th ed.). New York: The Guilford Press.

MacKinnon, D.P. (2007). Introduction to statistical mediation analysis. New York: Lawrence Erlbaum Associates.

Robins, R.W.., Fraley, R.C. \& Krueger, R.F. (2007). Handbook of Research Methods in Personality Psychology. New York: The Guilford Press. 